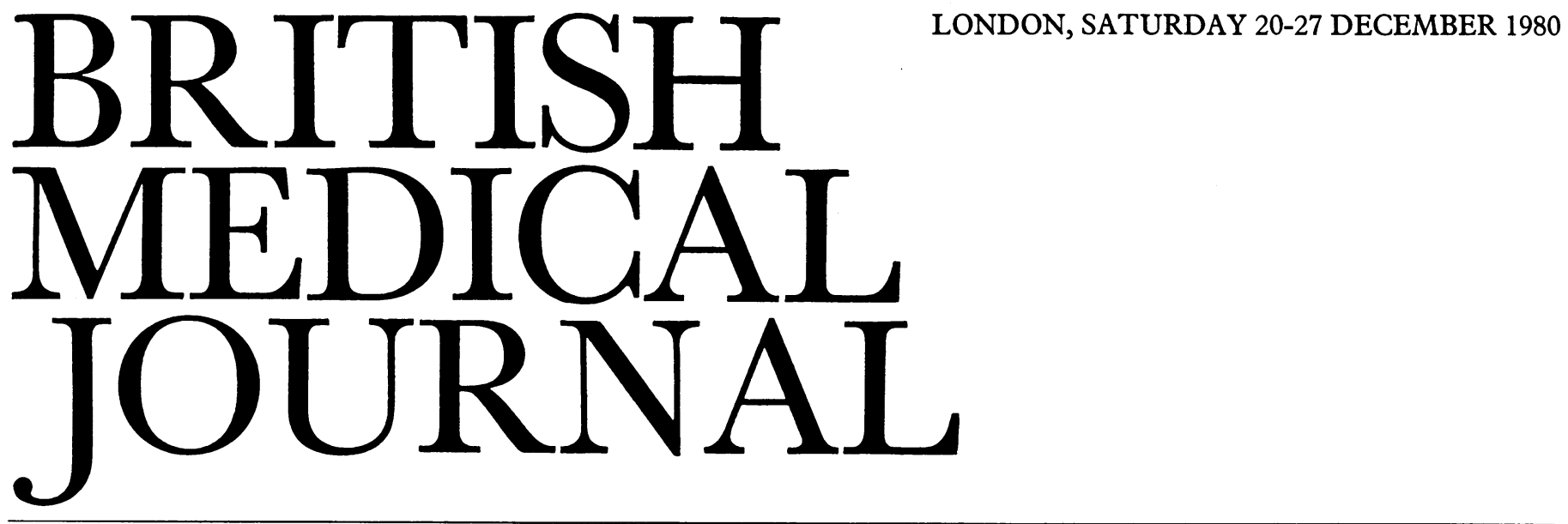

\title{
The Reith lectures: style, responsibility, and accountability
}

The autumn has been stormy for doctors and medicine. Hospitals have had an uphill struggle to maintain baseline services against resources decreasing in real terms; general practitioners have been coping with the implications of recession on the general wellbeing of countless families. Then came the Panorama debacle-a programme universally condemned by serious commentators but which has nevertheless become a cause célèbre. Though for once the political and academic voices of the profession reacted in unison, its public image seems to have come over yet again as authoritarian and defensive. Now, as a Christmas present, doctors have been given six of the best in the form of the Reith lectures, each 30 minutes of considered criticism of modern medicine-without an opportunity for a defence and thus fitting $\mathrm{Mr}$ David Dimbleby's unhelpful definition of the "party political broadcast."

The Reith lectures (all reprinted in the Listener) rarely fail to provoke controversy about some matter of legitimate public interest. This year's lecturer, Mr Ian Kennedy (reader in law and executive director of the Centre for Law, Medicine, and Ethics at King's College, London), called his series "Unmasking Medicine." At the risk of paraphrasing and misrepresenting his message it seems that Kennedy argues that doctors, albeit often unintentionally, have used illness as a concept of convenience to themselves, through which they have gained power to control the lives of their patients-the public. This power, Kennedy believes, is too often wielded for the benefit of doctor rather than patient and with insufficient contribution from patient or public in deciding the rules for its application. Quite correctly, he sees illness as a status as well as a pathological process and decisions on when health and illness are present as incorporating political and social as well as medical judgments. He complains about the worship of the cult of scientific medicine, regretting (as many doctors also do) that technology and the temptation to find new knowledge have leapfrogged each other in a way that has led to loss of control over both.

He joins the band of those who advocate reallocation of resources to support programmes aimed at preventing illness and reducing present inequalities of health care and then looks at the important and fundamentally difficult area of the basis of clinical judgments. He again attributes to doctors dominance and arrogance in making some of the most difficult of management decisions in human affairs (for example, resuscitation of severely handicapped babies, what to say to the patient with cancer, deciding the indications for termination of pregnancy) without recognising that he has sadly oversimplified dilemmas which cause agony to junior and senior doctors alike. Again, it seems that he creates unreal problems by talking so much more about the ethical and moral basis of compulsorily detaining 20000 mentally ill patients per annum (one per general practitioner) than about the five million people who each year go to family doctors for help with the problems of living. Finally, he lets himself go on the need to control the activities of doctors by audit (and through wider use of the courts, he wonders), perhaps failing to give enough thought to the philosophical point that if it is morally wrong for doctors to control patients it may not be any more right for patients to control doctors. After all of this, he concedes that he sees nothing sinister in the status quo-just some myths which need laying - and asks for fuller debate of the issues he has highlighted.

In reply we have to resist the temptation to overreact to the inevitable contradictions which any series of this nature must include; and we must avoid the temptation to make too much of the points where his lack of first-hand medical insight has allowed him to spoil his case by trivialising or generalising. We must, however, assert very strongly that the overwhelming majority of doctors find many of the ethical and moral issues that he raises as difficult and disturbing as he does. Above all, we must not just listen to the patient (Mr Kennedy) but try to hear what he is saying. For he raises at least three broad issues which ask for a prompt response.

Firstly, he criticises the way that we as doctors present ourselves to our patients. Kennedy's anxiety that technology has caused medicine to lose its way is shared by many; to a large extent doctors are now prisoners of their own success in responding to the challenges of imperfect knowledge of the subject. The belief that more knowledge and progress would be synonymous has probably always been more a patient's belief than a doctor's; but the treadmill is one that we are all now on and cannot easily get off. At the same time we ourselves are guilty of allowing our obsession with techniques to blind us to the often appalling indignities we cause our patients. We forget too easily that each consultation is unique for the patient, though it may seem repetitive to us. A barium enema, for example, may be nothing to the consultant reviewing a problem, or the registrar covering every remote possibility in his investigations, or the radiographer working through a routine list-but it is certainly something to the patient. And almost every hospital illness now inflicts on the patient one or more invasive procedures. What has tended to be lost is the 
sympathy, common sense, and good manners of medicinenot completely, perhaps not even most of the time, but certainly far too often. This too, we must recognise, is a problem more of hospital medicine than of general practice and more of teaching hospital medicine than of general hospital medicine. Thus as doctors we may seem to dictate when we should discuss, to dominate when we should defer, and to represent an establishment which is all too readily portrayed as insensitive and self-satisfied.

The second broad area of legitimate interest is the status of illness or being ill. Who takes decisions at the boundary where health stops and illness begins? Surely this time Mr Kennedy has his balance wrong. Most doctors-and, in particular, general practitioners-feel that routine decisions over, for example, whether a patient is able to work, whether he needs prescribed medicine, or whether referral to hospital is appropriate are already matters where it is the patient and public and not the doctor who plays the major part in determining what happens at a consultation. As a corollary, is it not time for doctors to complain more effectively about the substantial numbers of patients who persistently refuse to take responsibility for the care of minor and self-limiting illness and persistently disregard health warnings ? Often it is the pressures of quantity and nature of demand that wear doctors down to practising quick, opportunist, or impersonal medical care. If ever politicians could persuade the public to take a more realistic appreciation of the limitations which doctors face in attempting to explain, prevent, and abort every symptom experienced, then the necessary time to develop the better understanding between public and profession would be more readily found. There is little hope of relying on our politicians, however (see p 1662).

Lastly, Mr Kennedy has returned to the central problem of public accountability of monopolistic professional groups. Kennedy is only too right about the difficulties which face patients wanting to make complaints about what has or has not been done to them. He is, however, naive if he believes that doctors are unaffected by threats of inquiries into their professional work. The encouragement of more intervention by courts and lawyers in the relations between doctors and patients will not be seen by doctors as a constructive solution to a real problem. We all know-as Mr Kennedy surely does too-how poorly litigation correlates with fairness or even justice. Patients rarely complain when they have had a truly bad deal, and often when they do complain their complaints reflect factors extraneous to the medical care they have received. Contrary to what Mr Kennedy says, most doctors already value the benefits of intraprofessional audit; where it is realistic and sensitive they will co-operate in it, learn from it, and change their practice accordingly. But when it is the thin edge of the wedge of the control of professional judgment by political pressure, the response is clearly going to be more guardedand that is the response $\mathrm{Mr}$ Kennedy has sensed.

Despite our caveats, Mr Kennedy has stimulated many doctors and patients into looking seriously at important questions of widespread interest and sometimes concern. Some agree with most of what he has said; others have rejected much or all of it. Whether the public or the profession is more responsible for the problems $\mathrm{Mr}$ Kennedy has identified can and should be debated. If each suspects the other, unless one is grossly at fault, the best solution is probably to proceed cautiously rather than precipitately. Even $\mathrm{Mr}$ Kennedy stops short of accusing the medical profession of "anything sinister." Perhaps he will accept that within its walls a substantial reordering is taking place through debate within specialist groups, through continuous restructuring of undergraduate education, and through a steady upgrading of the quality and requirements of postgraduate training. $\mathrm{He}$ should be assured that in general doctors have retained their motivation to provide a true service-but it is now up to those same doctors to reassure the public by their everyday actions. Anything less may be seen as special pleading.

\section{Unquiet sleep}

About one in every 40 persons $^{1}$ walks in his or her sleep; the prevalence is higher in children than in adolescents or adults. Night terrors, in which the sleeper is greatly agitated, moves around restlessly, and may be hallucinated but then returns to sleep and has no recollection of the event, also occur mostly in childhood. Electroencephalographic recordings at night $^{2} 3$ have shown that both these phenomena occur characteristically in slow-wave (stages 3 and 4) sleep, one to three hours after the onset of sleep.

Sleepwalking and night terrors are known to run in families. A study of twins found that concordance was six times more common in monozygotic than in dizygotic twins, supporting a genetic mechanism. ${ }^{4} \mathrm{~A}$ recent investigation of 52 subjects has shown how frequently other members of the family are affected. ${ }^{5}$ In $80 \%$ of the sleepwalkers and $96 \%$ of those suffering from night terrors a first-degree, second-degree, or third-degree relative had one or both of these conditions. The familial pattern suggests a common physiological basis to the two conditions-a view supported by electroencephalographic studies-with night terrors representing the more extreme form. Probably both phenomena arise from the same basic neurophysiological disorder, partly genetically determined. Whether the disorder causes symptoms will depend on the degree of genetic liability and, in some cases, on the presence of stress. The gradual reduction in frequency of manifestation of the disorder with age seems likely to be due to maturation of the nervous system and the development of psychological coping mechanisms.

Lady Macbeth, probably the best-known fictional example of somnambulism, was a guilt-ridden woman whose nocturnal obsessional handwashing was closely related to the life stresses she brought on herself by her ambitious personality. How commonly is sleepwalking associated with stress and psychological disturbance? Studies of attenders at hospital clinics, who may well not be representative of those seen in general practice, suggest that associated psychiatric problems are more common in adults than in children; when they occur they are usually of neurotic type with depression and anxiety predominating. ${ }^{6}$ Most adult sleepwalkers $\left(81 \%\right.$ in one study $\left.{ }^{7}\right)$ regard their episodes as affected by mental stress, but this may less often be the case in children.

In the management of children the first step should be to establish whether the nocturnal episodes are the only symptoms or whether they form part of a wider disturbance. Possible areas of stress at home and school should be explored. Marital discord, psychiatric disorder in one or both parents, and excessive pressure to succeed at school are perhaps the most common background factors; sometimes these may respond to brief counselling. A severe problem which fails to respond to simple measures justifies referral to a child-and-family guidance clinic or to a child psychiatrist. 